\title{
DEL Dicho AL HECHO: El SEgURO POPUlAR, SU PRESUPUESTO Y LA ATENCIÓN A LA SALUD MATERNA eN Chiapas
}

\author{
Saying and Doing: "Seguro Popular" \\ -Social Health Insurance-, Budget \\ and Attention of Maternal Health in Chiapas
}

\section{Mónica Carrasco-Gómez ${ }^{1}$ Hilda Eugenia Argüello-Avendaño}

Resumen: En 2003 se implementa el Sistema de Protección Social en Salud —SPSS — o Seguro Popular — SP — como una estrategia a través de la cual el gobierno de México se comprometía a cumplir el derecho a la protección de la salud de toda persona sin seguridad social. SP es la instancia financiera que posibilita que los recursos públicos lleguen a los niveles de atención que se requieran. En más de diez años se han realizado acuerdos para la transferencia de recursos entre la federación y los estados que ascienden a miles de millones de pesos cada año. Estas entidades, al ser públicas, han de transparentar el uso de los recursos. Objetivo: Describir y analizar el funcionamiento de SPSS -Acuerdo de coordinación y el Anexo IV- de las intervenciones del Programa de Acción Específico Salud Materna y Perinatal —PAE SMyP - en Chiapas. Métodos: Revisión de normatividad, solicitudes de información y entrevistas a servidores públicos.

\footnotetext{
${ }^{1}$ Catedrática Conacyt, adscrita a CIESAS Sureste.

${ }^{2}$ Secretaria técnica del Observatorio de Mortalidad Materna en México y candidata a doctora en Antropología y Comunicación por la Universitat Rovira i Virgili, Tarragona.

Correos electrónicos: monica.carrasco@ciesas.edu.mx; hildaomm@gmail.com

Fecha de recepción: 3107 17; Fecha de aceptación: 011217.
}

(cc) EY-NC-ND Páginas 209-244. 
Palabras clave: rendición de cuentas, seguro popular, salud materna.

Abstract: In 2003, the Social Health Insurance —SPSS— or "Seguro Popular" - SP — was implemented as a strategy whereby the Mexican government committed itself to fulfill the right to health protection of every person without social security. The SP is the financial entity that enables public resources to reach the levels of care required. For over ten years agreements have been made in order to make possible the transfer of resources between the federation and the states. These resources amount to billions of pesos each year and because they are public, these agreements require transparency in the use of resources. Objective: To describe and analyze the functioning of the SPSS - Coordination Agreement and Annex IV - of the interventions of the Specific Action Program on Maternal and Perinatal Health - PAE SMyP - in Chiapas. Methods: Review of regulations, information requests and interviews with public servants.

Keywords: accountability, social protection system in health, maternal health.

\section{Introducción}

El Sistema de Protección Social en Salud —SPSS - o Seguro Popular - SP — es una política de salud que obedece a las directrices de gastar acertadamente y de manera focalizada en los sectores más vulnerables, acorde con las recomendaciones del Banco Mundial en 1993. El gobierno de México se comprometió a cumplir el derecho a la protección de la salud de toda persona sin seguridad social — casi la mitad de la población del país-. SPSS es el brazo operativo de dicho sistema, y desde 2003 funge como la instancia financiera que posibilita que los recursos federales, estatales y las cuotas familiares — requeridas según el nivel socioeconómico-, lleguen a los niveles de atención que se soliciten, 
convirtiéndose en la principal fuente de financiamiento de los programas de salud y de los servicios estatales de salud en todo el país.

Para operar esta política de salud a nivel estatal se realizó una separación de funciones entre la instancia financiadora y la que provee la atención o los servicios de salud. Adicionalmente se generaron Acuerdos de coordinación entre la federación y los estados, que al ser públicos permiten transparentar los procesos en el ejercicio de los recursos y sus resultados, lo que sienta las bases para la transparencia y rendición de cuentas, fundamental en el uso eficiente de los recursos y que además posibilita la contraloría social.

El presente documento hace uso de las herramientas que brinda el Instituto Nacional de Transparencia, Acceso a la Información y Protección de Datos Personales - Inai- a través del ejercicio del derecho al acceso a la información consagrado en el artículo $6^{\circ}$ constitucional, con el fin de identificar las posibilidades de mejora de procesos en el ejercicio de los recursos públicos destinados a ejercer el derecho a la salud que tiene toda la población mexicana.

\section{Metodología}

A través de la documentación y análisis de la información de las políticas federales y estatales de SPSS, principalmente obtenida mediante solicitudes de información en la Plataforma Nacional de Transparencia de Inai, y de la revisión normativa de fuentes oficiales y periodísticas, se obtuvieron resultados que requirieron de una serie de pesquisas para indagar en qué consiste el Acuerdo de Coordinación para la Ejecución del SPSS —ACESPSS — y su relación con el Programa de Acción Específico Salud Materna y Perinatal —PAE SMyP_; cuáles son las intervenciones de SMyP cubiertas por SP y cómo operan en el plano local. Para lo cual se hizo un seguimiento del ejercicio del recurso a nivel de las unidades médicas acreditadas por SPSS en el periodo 2014-2016. Asimismo, se solicitaron entrevistas a funcionarios del nivel federal —Centro Nacional de Equidad de Género y Salud Reproductiva, CNEGSR; Subsecretaría de Prevención y Promoción de la Salud, SPPS - y estatal — Régimen Estatal de Protección Social en Salud, REPSS—, las cuales sólo se concretaron con dos dependencias, 
Mónica Carrasco-Gómez

Hilda E. Argüello-Avendaño
Del dicho al hecho: El seguro popular, su presupuesto y la atención a la salud materna en Chiapas

CNEGSR y REPSS, en Chiapas. Sin embargo, aunque se requirió más tiempo para la obtención de la información, fue posible conseguirla a través de Inai.

\section{Antecedentes}

\section{El Estado mexicano como garante del derecho a la salud}

En 1917 se promulgó la Constitución de los Estados Unidos Mexicanos, que incluía el derecho de todas y todos los ciudadanos a la protección de la salud como garantía social. En 1923, en el ámbito de la salud materno-infantil, se implementó el Programa de Asistencia Materno Infantil, mismo que contempló la creación de clínicas de atención preventiva para las etapas prenatal y postnatal (Fernández, 1993: 23, en Argüello, 2017).

Posterior al periodo cardenista, México vivió un proceso de industrialización a la par del incremento de la clase obrera, por lo que en 1943 se creó el Instituto Mexicano del Seguro Social —IMSS — para proporcionar servicios médicos a los asalariados urbanos y al proletariado industrial (López, 1981: 103, en Argüello, s/f). El principal sustento financiero proviene de los recursos obrero-patronales y de aportaciones estatales, por tanto sus servicios se dirigen a quienes han pagado cuotas de afiliación, lo que se mantiene vigente hasta nuestros días. Unos años más tarde, en 1960, surgió el Instituto de Seguridad y Servicios Sociales de los Trabajadores del Estado - ISSSTE_ dado el crecimiento de la burocracia estatal y sus demandas asistenciales, otorgando servicios a los trabajadores de la federación (ibídem). En esa misma línea se crearon servicios de salud por parte de algunos organismos y empresas descentralizadas, como Petróleos Mexicanos, Ferrocarriles Nacionales, Comisión Federal de Electricidad, Secretaría de Marina, Secretaría de la Defensa Nacional y Secretaría de Hacienda y Crédito Público (ibídem).

En 1961, se inicia un proceso de delimitación de funciones en aras de asegurar el mejor aprovechamiento de recursos: la Secretaría de Salubridad y Asistencia — SSA — atenderá aspectos sanitarios asistenciales y preventivos; IMSS prestará servicios médicos a los trabajadores de la industria, e ISSSTE a la burocracia (Fernández, 1993: 16); a la población usuaria de estas dos últimas instituciones se le llamará "derechohabiente", 
y a la de SSA "no derechohabiente" o "población abierta". En los sesenta surgen el Instituto Nacional de Protección a la Infancia y la Institución Mexicana de Asistencia a la Niñez, mismos que se conjuntan en 1977 y se forma el Sistema Nacional para el Desarrollo Integral de la Familia —DIF (López, 1981: 103, en Argüello, s/f).

En sus inicios, IMSS e ISSSTE proveían servicios de seguridad social solamente a los trabajadores y sus familias. A finales de la década de 1980 e inicios de 1990 se incorporó a personas sin seguridad social, como estudiantes universitarios y transportistas (Laurell, 2001, en Watzkin, 2013: 190).

La población sin seguridad social, y que no pertenecían a estos últimos sectores incorporados, recibían atención por parte de la Secretaría de Salud —SS —. Sin embargo, los servicios no llegaban a toda la población, sobre todo por falta de instalaciones en las poblaciones rurales (Watzkin, 2013: 189).

\section{Focalizar el gasto en salud}

Una política pública de la década de 1990, cuyo impacto continúa en las estrategias, planes y programas vigentes, tanto en la esfera internacional como en la mexicana, surgió del "Informe sobre el Desarrollo Mundial 1993. Invertir en salud” del Banco Mundial. Este Informe recomendaba a los gobiernos cumplir con la obligación de gastar acertadamente, esto significaba asignar los recursos de forma en que se obtuviera el máximo mejoramiento posible de la salud o, por lo menos, que fuera notable a partir de un número relativamente reducido de intervenciones eficaces en función de los costos. Con ello se apuntaba a focalizar el gasto en acciones estrictamente necesarias, como la inversión en la salud de los pobres, mediante el diseño de estrategias que resultaran económicamente eficientes y socialmente aceptables para reducir la pobreza y aliviar sus consecuencias (Argüello, 2017).

El Banco Mundial propuso tres ejes que podrían incluirse en las políticas públicas destinadas a mejorar las condiciones de salud de los países en desarrollo (Banco Internacional de Reconstrucción y Fomento y Banco Mundial, 1993: iii): 
1. Acciones sobre el entorno. Apuntaba a implementar políticas de crecimiento económico que beneficiaran a los pobres; ampliar las inversiones en educación, particularmente de nińas, promoviendo la emancipación y empoderamiento de las mujeres (ídem: 6).

2. Mejorar las inversiones públicas en salud. Se encaminaba a reducir el gasto público de centros asistenciales de tercer nivel y de la formación de especialistas; y en cambio optar por financiar y asegurar la adopción de un conjunto de medidas de salud pública con gran externalidad — por ejemplo: vacunación, prevención del sida o accidentes por alcoholización-; financiar y asegurar la prestación de un conjunto de servicios clínicos esenciales, y mejorar la gestión de los servicios de salud estatales por medio de la descentralización de facultades presupuestarias y administrativas (ibídem).

3. Promover la diversidad y la competencia. Se alentaba a que los gobiernos se encargaran de financiar medidas de salud pública y servicios clínicos esenciales y que el resto fuera cubierto por los servicios privados (ibídem).

En 1995, integrantes del Departamento de Población, Salud y Nutrición del Banco Mundial publican las primeras propuestas (Bobadilla, Cowley, Musgrove y Saxenian, 1995) para diseñar e implementar un "paquete mínimo de intervenciones clínicas y de salud pública” a nivel nacional, con lo que se preveía disminuir entre 22 y $38 \%$ la mortalidad prematura y discapacidad en infantes menores de 15 años, y entre $10 \mathrm{y}$ 18\% la de la población adulta (ídem: 127).

En el documento de igual manera se discuten los criterios con los cuales determinar qué servicios incluir, el contenido de cada paquete, el costo y la forma de pago. El llamado era incorporar el análisis de los problemas de salud más importantes en los países de bajos y medianos ingresos, así como incluir a todos los grupos de edad. El paquete de servicios podía complejizarse a partir de las enfermedades prioritarias, los insumos y personal e instalaciones requeridos. La recomendación principal fue que los gobiernos se comprometieran a que la población pobre tuviese acceso a tales servicios. No obstante, los paquetes de servicios se centran en un enfoque económico de maximización de los 
beneficios, y no necesariamente contemplan ni garantizan el ejercicio del derecho a la salud sin restricciones.

\section{La reforma de salud en México}

El Sistema Nacional de Salud - SNS - en México es un conjunto de subsistemas, que atiende a diversas poblaciones, con diferentes suficiencias presupuestarias y alcances. De manera resumida podemos decir que pertenecen a éste las instituciones de seguridad social para los trabajadores asalariados y la Secretaría de Salud, que atiende a la población sin ningún tipo de cobertura. Un aspecto íntimamente relacionado con la utilización de los servicios de salud es el alto gasto de bolsillo que la población mexicana realiza, pues alcanza prácticamente $50 \%$ del gasto total en salud (OCDE, 2015). Es así que, para disminuir las brechas de acceso, desde la década de 1990 se empieza a gestar la organización del Sistema con el propósito de sacar el máximo provecho de los recursos mediante intervenciones focalizadas.

La reforma de salud impulsada en México a partir de 1995, con el apoyo financiero del Fondo Monetario Internacional y el Banco Mundial (Watzkin, 2013: 190), tuvo como finalidad separar las funciones del sistema de salud: 1) la rectoría es la encargada de conducir, regular, monitorear y vigilar la política nacional en salud; 2) el financiamiento se centra en la recaudación de fondos para cubrir las necesidades de salud, ésta puede ser colectiva o individual; 3) la prestación de servicios atiende a la población mediante la integración de las instituciones de salud y proveedores — públicos y privados.

En este contexto la propuesta de "pluralismo estructurado" (Londoño y Frenk, 1997: 8) crea una nueva función llamada articulación, que sería la mediadora entre el financiamiento y la prestación de servicios en un contexto de mercado regulado donde se compite por brindar la atención. ${ }^{3}$

\footnotetext{
${ }^{3}$ Como lo han documentado Laurell y Herrera (2010), se ha intentado en diversos momentos reformar el sistema de salud, primero en IMSS, luego con la puesta en marcha de SPSS en 2004, y posteriormente con la reforma al ISSSTE en 2007.
} 
Mónica Carrasco-Gómez

Hilda E. Argüello-Avendaño
Del dicho al hecho: El seguro popular, su presupuesto y la atención a la salud materna en Chiapas

\section{Funciones integradas, y su separación,}

en el sistema de salud mexicano

Una de las características de la seguridad social mexicana, en sus inicios, era que las funciones de financiamiento y prestación de servicios estaban integradas, por tal motivo se fortalecieron al tener infraestructura, recursos humanos e investigación propios para dar atención a 45\% de la población mexicana (Laurell y Herrera, 2010: 143).

La población sin seguridad social inicialmente era atendida por instituciones de asistencia pública, cuyo tipo de financiamiento era unipartito, provenía del gobierno federal, y representaba 15\% del gasto total en salud (Arredondo y Recaman, 2003: 11).

En los años 90, con los programas de extensión de cobertura, se brindó atención a algunos sectores sin seguridad social — sobre todo rurales - por parte de IMSS-Solidaridad, para algunos académicos ésta era una forma de alcanzar la universalización de los servicios de salud (Laurell, 2001: 23). El programa de reforma del sector salud publicado en 1996 se alineaba a las recomendaciones de focalizar el gasto, particularmente en los sectores menos favorecidos. Bajo esta perspectiva se creó SPSS como un mecanismo para brindar protección financiera a 55\% de la población que entonces carecía de seguridad social, a través de un paquete básico de intervenciones y utilizando la infraestructura del SS y de los Servicios Estatales de Salud (Sesa).

Al mismo tiempo, se abrió la posibilidad de subcontratar a farmacéuticas y/o distribuidoras privadas con el fin de que proveyeran insumos para la atención de algunos padecimientos de las intervenciones financiadas. Al respecto, Laurell y Herrera (2010) documentaron que un argumento central de la reforma era lograr la eficiencia del Estado y desalentar el mal manejo de los recursos, al dar el control financiero a un ente separado de la prestación de los servicios (Laurell y Herrera, 2010: 138).

Siguiendo a los mismos autores, no es sino hasta la segunda reforma o modernización del Estado que "el aseguramiento emerge como el mecanismo preferente de financiamiento para lograrla y para reducir gastos catastróficos e incrementar la equidad, además con la finalidad de mejorar la calidad y oportunidad de los servicios, incrementar la 
eficiencia y eficacia, abatir la corrupción y contener los costos" (ídem: 138). ${ }^{4}$

\section{Pasos hacia la integración funcional del sistema de salud}

En los primeros 15 años del siglo XXI, en México se empezaron a generar instrumentos de política pública con la finalidad de impulsar una integración funcional ${ }^{5}$ - IF_ de SNS (Ibarra et al., 2013: 311). IF se define como "la percepción, por parte de la población, de un horizonte plano de proveedores públicos, esto es, el acceso legal y sin barreras de cualquier residente en México a los servicios públicos de primer nivel y hospitalarios en función de residencia y necesidad de salud, sin importar la fuente de financiamiento" (Musgrove y González, 2007, en Ibarra et al. 2013: 311).

Asimismo, para lograr la IF del sistema era necesaria la separación de funciones entre los que prestan los servicios y los pagadores, estos últimos son denominados organizadores y administradores del consumo (ídem).

Con respecto a la salud materna, IF inició con el Programa de Acción Arranque Parejo en la Vida - APV-, creado por el gobierno federal en 2001 para atender los retos en salud materna, que logró su obligatoriedad en instituciones públicas y privadas en 2004 (INSP, 2008). Continuó con los Programas de Acción Específica - PAE_, APV (2007-2012), y PAE Salud Materna y Perinatal —SMyP(2013-2018).

En el periodo 2001-2003 se puso en marcha un proyecto piloto llamado Salud para Todos — precursor de SP_, como un instrumento de transferencia de subsidios a través de un paquete de servicios médicos, el cual inició su operación en cinco entidades federativas (Argüello, s/f).

SPSS surgió con el objetivo de proteger a la población que no contaba con seguridad social formal y que presentaba alto riesgo al empobrecimiento por gastos en salud. El 15 de mayo de 2003 se

\footnotetext{
${ }^{4}$ La primera reforma de salud en México fue en 1995, según Laurell y Herrera "el gobierno intentó transitar a un modelo de separación entre pagadores y proveedores con competencia de mercado" (2010: 143).

${ }^{5}$ Cabe mencionar que la fuente citada en dicho artículo no es localizable: Hacia la integración funcional del Sistema Nacional de Salud (SNS), Secretaría de Salud, México DF, 2011.
} 
adiciona a la Ley General de Salud la leyenda: "de la Protección Social en Salud”, con ésta SP se transforma de un programa a una ley (ibídem).

A partir de entonces, el SNS mexicano cuenta con tres esquemas de aseguramiento: el primero es la seguridad social, que en su funcionamiento están integrados el financiamiento y la prestación de servicios — por ejemplo, IMSS, ISSSTE, Pemex, Semar-. El segundo es SPSS, mecanismo financiero que tiene el propósito de asegurar la atención en salud a la población sin seguridad social, por medio de un paquete básico de intervenciones explicitado en el Catálogo Universal de Servicios de Salud - Causes - sin que los usuarios tengan que pagar al momento de su utilización. El tercer esquema son los seguros privados.

Para operar SP en las entidades federativas se establece el Acuerdo de Coordinación para la ejecución de SPSS —ACESPSS_- entre el nivel federal —SS — ${ }^{6}$ y el estatal —ejecutivo estatal $\_7$, que tiene la finalidad de "garantizar la protección social en salud, mediante el financiamiento y la coordinación eficiente, oportuna y sistemática de la prestación de los servicios de salud a la persona para contribuir a su acceso efectivo, eficaz y de calidad" 8 . Consta de tres apartados: I. Antecedentes, II. Declaraciones, y III. Cláusulas, a los que se suman ocho anexos. Los compromisos del Acuerdo los asumen SS, ${ }^{9}$ el ejecutivo estatal ${ }^{10}$ y el titular de

\footnotetext{
${ }^{6}$ El ejecutivo federal por conducto de SS, la cual es asistida por la subsecretaría de administración y finanzas, y por el Comisionado Nacional de Protección Social en Salud —CNPSS.

${ }^{7}$ El ejecutivo estatal, asistido por el Secretario General de Gobierno, el Secretario de Hacienda, el Secretario de Salud, el Secretario de la Función Pública y el Titular de REPSS.

${ }^{8}$ En los términos previstos por el título tercero bis de la Ley General de Salud SPSS.

${ }^{9}$ Entre los compromisos que asumen están: transferir con oportunidad al ejecutivo estatal los recursos que le correspondan para operar, por conducto de REPSS, las acciones de SPSS. Establecer en coordinación con el ejecutivo estatal los sistemas y procedimientos para llevar a cabo la supervisión, seguimiento, control y evaluación integral de REPSS en la operación del sistema y proporcionar la información que se tenga a los órganos competentes durante la fiscalización de los fondos que lo sustenten.

${ }^{10}$ Entre otras funciones, se compromete a "prestar a través de sus Servicios Estatales de Salud, los servicios de salud del CAUSES y del Fondo de Protección contra Gastos Catastróficos (FPGC), así como utilizar los recursos humanos, el suministro de insumos y medicamentos para su oferta oportuna y de calidad. Aplicar por conducto de EL REPSS los recursos que se reciban por concepto de Cuota Social, aportación solidaria federal y estatal. Participar a través de su Secretaría de Contraloría en las acciones de supervisión, seguimiento, control y evaluación integral del REPSS en la operación del SPSS en el ESTADO, así como respecto de los recursos presupuestarios y/o en especie que para la ejecución del SPSS le sean transferidos. Reportar mensualmente la compra de medicamentos efectuada para la operación del SPSS”.
} 
REPSS. ${ }^{11}$ Todos los actores descritos manifiestan que el ejecutivo estatal garantizará la prestación de los servicios de salud a los beneficiarios de SPSS: cubiertos por Causes y por el Fondo de Protección contra Gastos Catastróficos (FPGC), especificado en el Anexo I.

El compromiso de incorporar personas previsto para cada año sería acordado con SS por conducto de CNPSS. Las metas anuales de incorporación con base en las cuales se determinarán los recursos que se transferirán al Estado se incluyen en el Anexo II. La asignación de los recursos presupuestarios, así como la entrega de aquellos en especie se especifican en el Anexo III. Finalmente, los recursos federales que se transfieran al ejecutivo estatal para la ejecución de SPSS no podrán ser destinados a fines distintos a los expresamente previstos en el Anexo IV. En este mismo Anexo se establecerán, en cada ejercicio fiscal, con base en lo dispuesto por el Presupuesto de Egresos de la Federación y las demás disposiciones aplicables, los conceptos de gasto, los límites máximos para cada uno de ellos, entre otras disposiciones generales.

El Anexo V se refiere a la tutela de Derechos; en el Anexo VI se explicita el procedimiento para llevar a cabo acciones de infraestructura física; en el Anexo VII se describen los indicadores de seguimiento a la operación y los términos de evaluación integral de SPSS, y finalmente el Anexo VIII establece los criterios generales en materia de supervisión. En términos de rendición de cuentas, ACESPSS estipula que:

Los recursos federales que el EJECUTIVO ESTATAL reciba del FPGC y de la previsión presupuestal, a través de su tesorería local ... deberán ser ministrados íntegramente ... en caso de incumplimiento la CNPSS informará a la Auditoría Superior de la Federación, a la Secretaría de la Función Pública y al órgano de control interno para efectos legales y administrativos que procedan (SS, 2015: 12).

\footnotetext{
${ }^{11}$ Las actividades de las que se hará cargo REPSS son las siguientes: administrar y supervisar el ejercicio de los recursos; financiar, coordinar y verificar de forma eficiente, oportuna y sistemática la prestación integral de los servicios a la persona, a cargo de los establecimientos para la atención médica incorporados a dicho SPSS, en la que se incluya atención médica, los medicamentos y demás insumos asociados. Gestionar el pago a los establecimientos. Reintegrar los recursos en numerario de carácter federal que no haya ejercido o comprobado su destino. Rendir cuentas respecto a los recursos que reciban. Entregar la información que las autoridades federales o locales competentes le soliciten respecto a los recursos que reciban.
} 
Es por tal motivo que el Anexo IV de ACESPSS cobra gran relevancia, pues es la ventana al ejercicio de transparencia donde tiene que estipularse cómo gastan los recursos para garantizar la protección social en salud.

\section{Otros acuerdos y convenios encaminados a la IF del sistema}

El Acuerdo para el Fortalecimiento de las Acciones de Salud Pública en los Estados - AFASPE - es una política pública implementada desde 2008 que transfiere recursos e insumos — de la federación a los estados- desde la Subsecretaría de Prevención y Promoción de la Salud (SPPS) de SS a Sesa (Argüello, 2017: 89), destinados actualmente a 36 programas de acción entre los cuales se encuentra PAE SMyP. El Acuerdo se formaliza a través de un Convenio anual que especifica las metas comprometidas por parte de las entidades federativas, los recursos en numerario y en insumos por programa, y es publicado por SPPS. El convenio incluye la fecha de ministración de los recursos monetarios, así como cinco anexos y un apéndice. El anexo segundo es particularmente importante para la transparencia y rendición de cuentas porque se identifican las diferentes fuentes de financiamiento de cada programa: los recursos provenientes del Ramo 12 de SPPS y materia del convenio, como los que provienen de CNPSS, específicamente del Anexo IV. El apéndice también es relevante en el mismo sentido, ya que además de la información del Anexo 2 incluye el Ramo 33 o Fassa y la aportación estatal, por lo que posibilita contar con la información del presupuesto total de cada programa por fuente de financiamiento. No existen otros instrumentos que brinden esta información de manera pública.

El resto de anexos del convenio también contribuye en diferentes sentidos a la transparencia y rendición de cuentas: el Anexo 1 contiene las firmas de las partes que lo celebran; el Anexo 3 especifica las fechas de ministración de los recursos en numerario; el Anexo 4 los indicadores y metas de cada programa, y el Anexo 5 detalla los insumos que serán enviados en especie.

Otro instrumento dirigido a IF del sistema es el Convenio General de Colaboración Interinstitucional para la Atención de la Emergencia Obstétrica - CGCIAEO - entre IMSS, ISSSTE, SS e IMSS-Prospera —incluido en 2013 — , encaminado a la universalización de los servicios 
de salud, fue creado en 2009 por decreto presidencial. CGCIAEO apuesta por la portabilidad de los recursos de manera individual —la atención será pagada a la institución que otorgue el servicio- y a los pagos cruzados de los servicios entre las instituciones participantes; sin embargo, como ha documentado el Observatorio de Mortalidad Materna en México a través de monitoreos realizados a esta política pública, los resultados evidencian una limitada colaboración entre las instituciones, ausencia de redes interinstitucionales, así como burocracia y dilación en el pago de servicios, entre otros (OMM, 2015).

Un tercer instrumento es el Acuerdo General de Colaboración para el Intercambio de Servicios, formalizado el 12 de mayo de 2011 entre las instituciones públicas de SNS, cuyo objetivo es establecer los lineamientos generales para la formalización de los compromisos que permitan intercambiar servicios de atención médica entre IMSS, ISSSTE, SS y Sesas, por medio de la definición y adopción del Catálogo Nacional de Servicios, Intervenciones, Auxiliares de Diagnóstico y Tratamiento, y el Tabulador de Tarifas Máximas Referenciales, con la finalidad de incidir en la optimización de la infraestructura y recursos disponibles del sector salud para la atención de la salud, mejorar la oportunidad y la calidad de los servicios de atención médica y brindar posibilidades de atención a grupos de población con padecimientos específicos y protección de los mexicanos (SS, 2011).

\section{ANÁlisis DE LOS PRESUPUESTOS SOBRE SALUd MATERNA}

Los trabajos que han enfatizado la rendición de cuentas en la mortalidad y morbilidad materna provienen de los enfoques basados en derechos humanos (Langford, 2008: 7; Yamin, 2010: 100). La Organización de las Naciones Unidas retoma el planteamiento de "constructive accountability" o rendición de cuentas constructiva de Freedman L. (2003), cuya propuesta consiste en fortalecer el sistema sin buscar culpables ni castigos, sino desarrollando una dinámica de ejercicio del derecho entre la gente y sus gobernantes dentro del sistema de salud que la beneficie. Así ONU manifiesta que "el derecho a la salud exige la rendición de cuentas de diferentes interesados, particularmente los proveedores de la asistencia sanitaria, las autoridades locales de salud, 
los gobiernos, las organizaciones internacionales y la sociedad civil" (ONU, 2006: 10). De igual manera las organizaciones civiles se han concentrado en promover una rendicion de cuentas eficaz (Human Right Watch, 2009).

En este sentido, Yamin abona a la discusión de los derechos humanos y la rendición de cuentas siguiendo la propuesta de la "rendición de cuentas constructiva”, por lo que es necesario ir más allá del modelo de castigo y propone concentrarse en factores institucionales y sistémicos, pero sobre todo en el papel activo de la participación popular. Es decir, propone hacer un análisis e intervención en los procesos que incluya "la implementación de un plan nacional de acción, análisis presupuestarios, monitoreo y evaluación de programas sobre la base de indicadores adecuados y mecanismos de reparación" (Yamin, 2010: 97-127).

En América Latina, a la luz de los compromisos internacionales y específicamente sobre el quinto objetivo de desarrollo del milenio, que pretendía disminuir la mortalidad materna, las organizaciones civiles ante el lento avance para el logro de éste, empezaron a cuestionar si los recursos que obtenían los Estados de los organismos multilaterales y de los propios presupuestos nacionales se ejercían de manera eficiente. Por lo cual se propusieron analizar la transparencia en el financiamiento, y encontraron diversos obstáculos para lograr monitorearlo así como disparidades en la manera de capturar los datos y dar segumiento a los avances locales (Malajovich, Alcalde, Castagnaro y Barroso, 2012: 185).

Los presupuestos en salud en México (Díaz, 2012), y específicamente en Chiapas, han sido analizados desde el enfoque de género explorando SPSS como política pública (Morales, Sánchez y Kauffer, 2011), y la rendición de cuentas y el análisis del desempeño de una política nacional para la atención de la salud materna a través de sus transferencias monetarias por parte de AFASPE en Chiapas (Freyermuth, Pérez y Argüello, 2014 ). En estos trabajos se recomiendan acciones específicas para que los servidores o funcionarios públicos — quienes son protagonistas de los procesos de ejecución y utilización de los recursos- así como la sociedad civil organizada tengan una mayor participación y con ello mejorar los procesos. 


\section{Hallazgos \\ Operación de SPSS}

La separación de funciones es un requisito para operar SPSS. CNPSS está a cargo de la planeación, coordinación y regulación de éste, mientras que el monto del financiamiento federal brindado a los estados depende del número de afiliados anualmente. De esta manera, cada entidad federativa recibe una cuota federal, brinda una cuota estatal y recauda una cuota familiar, dejando la administración de fondos y la compra de servicios, "función articulación", a dos nuevos organismos desconcentrados: CNPSS y REPSS.

Además, la "cobertura universal" está contenida en un paquete de intervenciones reunidas en Causes, que en el año 2016 cubría 287 intervenciones con sus medicamentos y estudios de gabinete, y de éstas 42 son de salud materna:

\begin{tabular}{|l|l|}
\hline \multicolumn{2}{|c|}{$\begin{array}{c}\text { Diagnóstico y tratamiento que brindan las intervenciones de Causes } 2016 \\
\text { en Salud materna y perinatal }\end{array}$} \\
\hline $\begin{array}{l}\text { 28 Anemia ferropriva y por deficiencia } \\
\text { de vitamina B12 }\end{array}$ & 218 Diabetes gestacional \\
\hline 93 Atención prenatal del embarazo & $\begin{array}{l}219 \text { Hipertensión inducida y/o preexis- } \\
\text { tente en el embarazo }\end{array}$ \\
\hline 182 Amenaza de aborto & $\begin{array}{l}220 \text { Trombosis venosa profunda en el } \\
\text { embarazo y puerperio }\end{array}$ \\
\hline 183 Amenaza de parto pretérmino & $\begin{array}{l}\text { 243 Quirúrgico de enfermedad trofo- } \\
\text { blástica }\end{array}$ \\
\hline $\begin{array}{l}\text { 184 Atención del parto y puerperio } \\
\text { fisiológico }\end{array}$ & 244 Embarazo ectópico \\
\hline 185 Pelviperitonitis & $\begin{array}{l}245 \text { Aborto incompleto (no incluye } \\
\text { interrupción legal del embarazo) }\end{array}$ \\
\hline 186 Endometritis & $\begin{array}{l}246 \text { Atención de cesárea y puerperio } \\
\text { quirúrgico }\end{array}$ \\
\hline 187 Choque séptico puerperal & 247 Reparación uterina \\
\hline 188 Atención del recién nacido & 45 Gonorrea \\
\hline 189 Icteria neonatal & $\begin{array}{l}46 \text { Infecciones por Chlamydia } \\
\text { (incluye tracoma) }\end{array}$ \\
\hline $\begin{array}{l}190 \text { Recién nacido pretérmino sin } \\
\text { complicaciones }\end{array}$ & \begin{tabular}{l}
47 Trichomoniasis \\
\hline
\end{tabular}
\end{tabular}




\begin{tabular}{|l|l|}
\hline \multicolumn{2}{|c|}{$\begin{array}{l}\text { Diagnóstico y tratamiento que brindan las intervenciones de Causes } 2016 \\
\text { en Salud materna y perinatal }\end{array}$} \\
\hline $\begin{array}{l}191 \text { Recién nacido pretérmino con } \\
\text { hipotermia }\end{array}$ & 48 Sífilis precoz y tardía \\
\hline $\begin{array}{l}192 \text { Recién nacido pretérmino con bajo } \\
\text { peso al nacer }\end{array}$ & 49 Cistitis \\
\hline 193 Preeclampsia leve y moderada & 50 Vaginitis aguda \\
\hline 194 Preeclampsia severa & 51 Vulvitis aguda \\
\hline 195 Eclampsia & 52 Chancro blando \\
\hline $\begin{array}{l}196 \text { Hemorragia obstétrica puerperal } \\
\text { (incluye choque hipovolémico) }\end{array}$ & 53 Herpes genital \\
\hline $\begin{array}{l}\text { 197 Hemorragia por placenta previa y } \\
\text { desprendimiento prematuro de placen- } \\
\text { ta normoinserta }\end{array}$ & $\begin{array}{l}\text { 91 Consejo y asesoramiento general } \\
\text { sobre anticoncepción mediante el uso } \\
\text { del condón }\end{array}$ \\
\hline $\begin{array}{l}\text { 198 Infección de episiorrafia o herida } \\
\text { quirúrgica obstétrica }\end{array}$ & $\begin{array}{l}\text { 92 Método de planificación familiar } \\
\text { temporal con dispositivo intrauterino }\end{array}$ \\
\hline 215 Síndrome de HELLP & 141 Focos infecciosos bacterias \\
\hline 216 Corioamniotitis & 217 Embolia obstrética \\
\hline
\end{tabular}

La prestación de los servicios médicos son responsabilidad de Sesas y otros prestadores de diversas figuras legales, entre ellos, la iniciativa privada. SP opera en los estados a través de ACESPSS, que especifica los compromisos entre la federación y los estados para brindar servicios, ejercer recursos presupuestales, asignar los conceptos de gasto, tutelar derechos y los procedimientos para llevar a cabo acciones de infraestructura, entre otros.

No obstante, esta nueva forma de administrar los recursos desde la federación a las entidades federativas ha sido señalada por parte de la Auditoría Superior de la Federación —ASF_, como opaca y poco transparente en la asignación — no establece el monto ni calendario-; transferencias - no toma en cuenta las particularidades del sector en las diversas entidades; retraso en la entrega de recursos; mezcla de recursos de otros programas y su difícil seguimiento-; ejercicio y destino de los recursos — subrogación a entes privados y adquisiciones de insumos con elementos de opacidad (ASF, 2013).

Ante estas llamadas de atención, SPSS reforma en 2014 el reglamento de la Ley General de Salud en un esfuerzo por transparentar el uso de 
recursos públicos y mejorar la calidad de atención, otorgándole mayor responsabilidad a REPSS para administrar y supervisar el ejercicio de recursos financieros, es decir, cumpliendo la función de articulación.

\section{Obligaciones de transparencia}

En este contexto REPSS y SPSS, de los estados y la federación, deben publicar información sobre universos, coberturas, servicios ofrecidos, manejo financiero e informes; en caso de incumplimiento CNPSS informará a ASF, así como a la Secretaría de Función Pública y al Órgano de Control Interno, para los efectos legales que se deriven. Sin embargo, esta información no estuvo disponible en las páginas web oficiales de Chiapas, de ahí que la información se solicitara a Inai (ver Cuadro 1).

Cuadro 1. Información que debería estar disponible en las páginas web de SPSS en los estados, caso Chiapas 2016.

\begin{tabular}{|l|l|}
\hline \multicolumn{1}{|c|}{ Rubros a considerar } & \multicolumn{1}{c|}{ Estatus } \\
\hline Universo poblacional & No Disponible \\
\hline Cobertura (intervenciones Causes y FPGC) & Disponible \\
\hline Servicios ofrecidos & No Disponible \\
\hline $\begin{array}{l}\text { Manejo financiero } \\
\text { (Informes financieros y de gestión) }\end{array}$ & Incompleto \\
\hline $\begin{array}{l}\text { Número y tipo de las plazas existentes, } \\
\text { movimientos que se realicen a dichas plazas }\end{array}$ & Desactualizado \\
\hline $\begin{array}{l}\text { Relación de trabajadores comisionados por centro } \\
\text { de trabajo, identificando sus claves de pago, } \\
\text { el centro de trabajo de origen }\end{array}$ & Incompleto \\
\hline $\begin{array}{l}\text { Relación de personas contratadas por honorarios, } \\
\text { por centro de trabajo }\end{array}$ & No Disponible \\
\hline $\begin{array}{l}\text { Acuerdos de coordinación } \\
\text { para la ejecución de SPSS y sus ocho anexos }\end{array}$ & Incompleto y desactualizado \\
\hline Mecanismos de participación ciudadana & No Disponible \\
\hline $\begin{array}{l}\text { Nombre de proveedor, clave del medicamento, } \\
\text { unidades, monto unitario } \\
\text { y procedimiento de contratación }\end{array}$ & No Disponible \\
\hline
\end{tabular}

Fuente: M. Carrasco-Gómez, con datos de SPSS de Chiapas, en http://www. seguropopularchiapas.gob.mx/principal/ [fecha de consulta: 15 de septiembre de 2016] 


\section{Funcionamiento de ACESPSS en Chiapas}

En ACESPSS, y con base en el artículo 77 bis 15 de la Ley General de Salud, ${ }^{12}$ se explica la ruta de los recursos pero únicamente de la federación a las entidades federativas, y es en el Anexo IV donde se desprende de ACESPSS que se establecen los conceptos de gasto en las entidades federativas. ${ }^{13}$

En este proceso de transferencia se puede identificar la re-centralización en el manejo de los recursos financieros, debido a que el dinero que se brinda en numerario a los estados se mantiene en una cuenta en la Tesorería de la Federación - Tesofe- y REPSS sólo da suficiencia presupuestal a Sesa (ver Figura 1).

Figura 1. Rendición de Cuentas en el Acuerdo de coordinación.

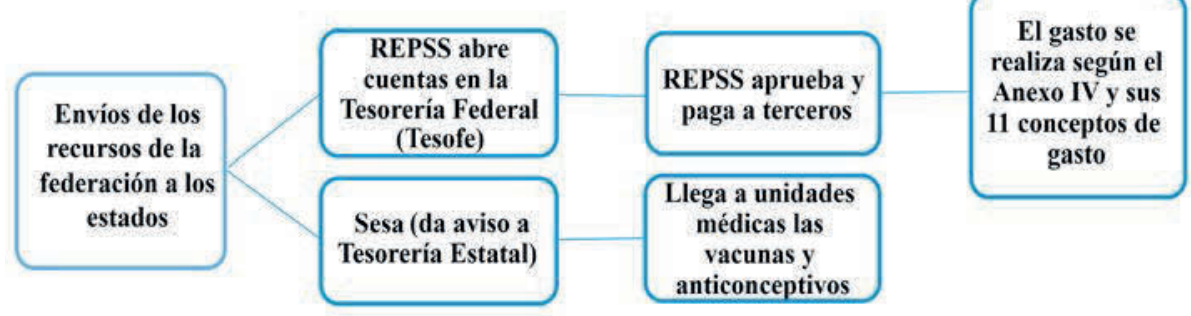

REPSS: Regímenes Estatales de Protección Social en Salud, tienen que informar a SS en tres días hábiles montos, fechas e importe de rendimientos.

Sesa: Servicios estatales de salud.

Terceros: farmacéuticas o distribuidoras privadas.

${ }^{12}$ El gobierno federal transferirá a los gobiernos de las entidades federativas los recursos que por concepto de cuota social y de aportación solidaria le correspondan, con base en las personas afiliadas que no gocen de los beneficios de las instituciones de seguridad social, validados por la Secretaría de Salud.

${ }^{13} 1$. Remuneraciones al personal ya contratado, directamente involucrado en la prestación de servicios de atención a los beneficiarios del sistema; 2 . Adquisición de medicamentos, material de curación y otros insumos necesarios para la prestación de servicios a los afiliados al sistema; 3. Acciones de promoción, prevención y detección oportuna de enfermedades que están contenidas en Causes; 4. Gasto operativo y para el pago de personal administrativo de REPSS; 5. Fortalecimiento de Infraestructura de Unidades Médicas -FIUM-; 6. Acreditación de los establecimientos médicos que prestan servicios al sistema; 7. Programas de Caravanas de la Salud; 8. Adquisición de Sistemas de Información y Bienes informáticos; 9. Pagos a terceros por Servicios de Salud; 10. Pago por servicios a Institutos Nacionales, Hospitales Federales y Establecimientos de Salud públicos; 11. Gasto operativo de Unidades Médicas participantes en la prestación de Causes. 


\section{Ejercicio de recursos a nivel de unidades médicas en Chiapas}

En ACESPSS, REPSS funciona como articulador y se encarga de abrir cuentas en la Tesorería de la Federación — Tesofe-y aprobar los pagos que Tesofe realice a terceros (Secretaría de Salud, 2015). No obstante, en estos acuerdos y anexos no se menciona cómo se deberá enviar el recurso a las unidades médicas.

Es así que se hicieron solicitudes sobre el ejercicio de los recursos a nivel municipal y en las unidades médicas, sin embargo SS, CNPSS y REPSS no dieron respuesta, argumentando que no eran los sujetos obligados a ello. No obstante, se interpusieron recursos de inconformidad que se ganaron, y éstas instancias tuvieron la obligación de responder, pero el Instituto/Secretaría de Salud del Estado de Chiapas - Isech - declaró la inexistencia de ese tipo de información, argumentando no tenerla por "no ser una particularidad de obligatoriedad" (Secretaría de Salud del Estado de Chiapas, 2015).

Fue en este marco que se solicitaron entrevistas a funcionarios de REPSS. Al respecto, los principales hallazgos a partir de la entrevista al director de gestión de Servicios de Salud son:

1. Descripción de una ruta general de distribución de los recursos.

2. El cambio en el proceso de distribución de los recursos a partir de la modificación a la Ley General de Salud en materia de Protección Social en Salud en 2014, que implicó la descentralización de REPSS, con el fin de brindarle mayor autonomía de gestión, personalidad jurídica y patrimonio propios, confiriéndole así mayor responsabilidad en el uso de recursos.

3. El aporte económico de la federación que llega a Chiapas se ejecuta de la siguiente manera:

a) Para que los recursos lleguen a las unidades médicas, Isech efectúa proyectos para las unidades médicas acreditadas por SP, basadas en las necesidades de las mismas.

b) REPSS brinda suficiencia presupuestaria para la ejecución de los recursos y se realizan los pagos autorizados por la federación a través de Tesofe. No hay depósitos directos de los recursos en numerario a Isech ni a las unidades médicas. 
c) Entre lo que programa Isech y lo que reciben las unidades médicas, los intermediarios son las empresas o instituciones ${ }^{14} \mathrm{y}$ el área de recursos humanos y materiales de Isech que abastecen de insumos a las unidades médicas.

d) A las unidades médicas les llegan los recursos en especie - insumos.

(Entrevista al director de gestión de Servicios de Salud, Tuxtla Gutiérrez, Chiapas, 12 de julio de 2016.) (Ver Figura 2.)

Figura 2. Ruta del recurso económico del Anexo IV de ACESPSS en el estado de Chiapas.

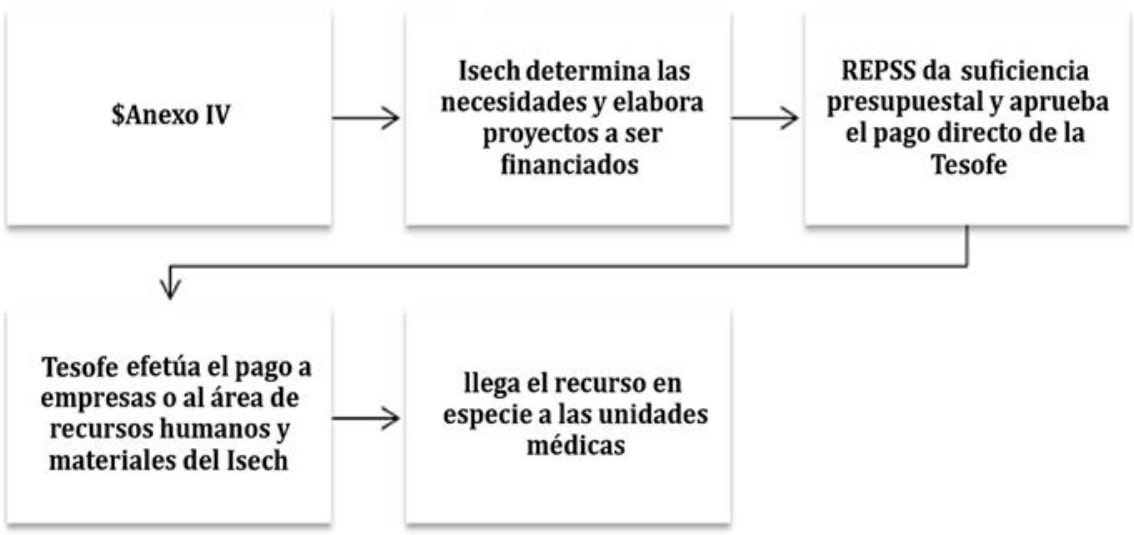

REPSS no deciden la manera en cómo se distribuye el dinero. Las necesidades las determinan Sesa bajo los porcentajes que se estipulan en el Anexo IV. REPSS sólo controlan el financiamiento para el pago de los servicios, insumos o equipamiento de los proyectos respecto a lo que ejecuta el instituto de salud. Isech efectúa los proyectos y los envía a REPSS para su aprobación (entrevista a director de gestión de Servicios de Salud, Tuxtla Gutiérrez, Chiapas, 12 de julio de 2016).

\footnotetext{
${ }^{14}$ Los proveedores de servicios pueden ser sociedades anónimas de capital variable, instituciones de asistencia privada, personas físicas, organismos públicos descentralizados, sociedades de responsabilidad limitada e instituciones de beneficencia privada.
} 


\section{Ejercicio de los recursos del Anexo IV en Chiapas, 2014-2015}

En 2014, Chiapas recibió por el Anexo IV la cantidad de $\$ 3,805,003,350$. En septiembre de 2015, aún no habían comprobado esos recursos. En la respuesta a la solicitud de información se reportaba como no ejercido. ${ }^{15}$ Se replicó la misma solicitud en julio de 2016 y en la correspondiente respuesta comprobaban que el recurso se había ejercido en su totalidad. ${ }^{16}$ Sin embargo, las cifras no concuerdan para el ejercicio 2015, esto porque en la primera solicitud — septiembre de 2015 - el total reportado era $\$ 3,855,267,918.00$, pero en la segunda solicitud — julio de 2016 - el total programado y ejercido fue $\$ 3,786,450,054.94$; en otras palabras, faltaban $\$ 68,817,863.06$.

En una indagación más exhaustiva se solicitaron los contratos trimestrales que reportan las entidades a SPSS. Pero sólo fue posible acceder a los contratos del tercer trimestre del año 2014 a proveedores de servicios, los cuales van de $\$ 54.7$ millones de pesos con sociedades anónimas, 10.3 millones de pesos con personas físicas, a 26 mil pesos con ISSSTE, 19 mil pesos con la Cruz Roja Mexicana, y se incluyen más de 18 mil pesos con personas físicas que se llaman "Z" o "Mu" (CNPSS, 2016).

Según la información recabada, existen otras transferencias hacia los proveedores de servicios cuando una persona beneficiaria de SPSS sea atendida en cualquier establecimiento de salud del sector público de carácter federal. Al suceder lo anterior SS canalizará directamente a dicho establecimiento el monto correspondiente a las intervenciones prestadas, con cargo a los recursos que se transfieren al respectivo REPSS, de acuerdo con los lineamientos que para tal efecto emita la propia SS; sin embargo, la información sobre los pagos a [...]

\footnotetext{
${ }^{15}$ Respuesta a la solicitud de información con número de solicitud 1210200017015 y con oficio de la Dirección General de Administración y Finanzas No. CNPSS-UE-418-2015.

${ }^{16}$ Con el número de solicitud 1210200014716 y con oficio de respuesta CNPSS-UT-502016.
} 
proveedores por intervenciones no están disponibles para la consulta, porque SPSS a través de sus direcciones responde que no la genera. ${ }^{17}$

Acerca de las intervenciones de salud materna fue posible obtener información sobre los montos programados, pero no de los ejercidos. Al respecto, es posible discutir la inexistencia de dicha información, debido a que las entidades federativas reportan la compra de servicios por entidad-proveedor-padecimiento y la suben al portal de sistemas de SPSS, y aunque esta información no es pública se pudo acceder por el enlace proporcionado en una respuesta a Inai, aunque los tres padecimientos desplegados no incluían intervenciones de salud materna ${ }^{18}$ (titular de la unidad de Transparencia, 2016). Además de la información brindada sobre los montos programados, CNPSS aclaró que:

... el gasto del $20 \%$ para acciones de promoción, prevención y detección oportuna de enfermedades que estén contenidas en el CAUSES es un concepto de gasto transversal por lo que se contabilizan todos los conceptos de gasto tales como las remuneraciones del personal, los medicamentos, el material de curación y otros insumos, el equipamiento y caravanas. La premisa para esta comprobación, es que dichos gastos incidan en las acciones de promoción, prevención de la salud y en la detección oportuna de enfermedades (ídem).

Por lo tanto, CNPSS aclara que realiza la fiscalización de los recursos de las entidades federativas por concepto de gasto correspondiente al Presupuesto de Egresos de la Federación - PEF — y al Anexo IV de

${ }^{17}$ Inicialmente, en diversas direcciones generales — de financiamiento, de gestión de servicios de salud, etc.- declararon que no eran del ámbito de su competencia (oficio CNPSS/ DGGSS/2036/2016, de 17 de agosto de 2016) y aunque el recurso de revisión fue declarado con fundamentos y le solicitaron a la dirección general de Coordinación con Entidades Federativas que brindara la información, la declararon inexistente. Respetando el principio de máxima publicidad, la dirección general de financiamiento proporcionó los informes remitidos por CNPSS sobre el ejercicio de los recursos de Cuota Social y Aportación Solidaria Federal transferidos en Acciones de Prevención y Promoción de la Salud, correspondientes a los ejercicios fiscales 2013, 2014 y 2015 de Chiapas.

18 Documento que dio cumplimiento a la resolución recaída en el recurso de revisión RRA3558/16 a cargo de CNPSS. Solicitud 1210200018016, del expediente: RRA3558/16. El link al que se hace referencia es http://sistemas.cnpss.gob.mx:7000/data_mart/index.php/ dm_servicios/index/201403 
ACESPSS y no por programa, como sería el de SMyP o por las intervenciones de Causes. CNPSS también menciona que:

... las entidades federativas reciben recursos de otras fuentes de financiamiento como el Ramo 12 y 33, de los cuales, para las acciones de prevención y promoción los recursos son destinados por programa y deben alinearse a las políticas establecidas por la SPPS por lo que dicha subsecretaría cuenta con la plataforma SIAFASSPE y firma el AFASPE con cada entidad. En este sentido, para la entidad federativa que va a realizar la programación resulta complejo efectuar dos programaciones por ser distintos recursos ${ }^{19}$ para las mismas acciones de prevención y promoción, por lo que se simplifica el trámite y se realiza una sola programación de recursos, en la plataforma SIAFFASSPE y se sujeta a la comprobación del gasto por cada fuente de financiamiento (titular de la unidad de Transparencia, 2016: 14). ${ }^{20}$

Además, CNPSS no participa en la formalización de los convenios AFASPE, tal como lo refiere el Apéndice del citado convenio. Los recursos de SPSS se señalan únicamente para efectos informativos, por lo que su aplicación, ejercicio y comprobación es responsabilidad de quienes tienen a cargo dichas fuentes de financiamiento que para el caso son las entidades federativas; ${ }^{21}$ como se mencionó, para SPSS la comprobación se realiza por concepto de gasto, es decir, el total de medicamentos comprados.

En razón de lo anterior, las acciones y conceptos de gasto de SPSS deben estar vinculadas a Causes, por lo que para favorecer dicha simplificación administrativa, a través de la Dirección General de Gestión de Servicios de Salud _DGSS_, se validan los recursos alineados a las intervenciones de Causes y vinculados a los PAE de SPPS. A efecto de que las entidades federativas puedan realizar una sola programación acorde con las diferentes fuentes de financiamiento, el Anexo IV de ACESPSS es validado por DGSS en conjunto con SPPS. Sin embargo, DGSS informó sobre el proceso pero mencionó no

\footnotetext{
${ }^{19} \mathrm{El}$ subrayado es de las autoras.

${ }^{20}$ Solicitud 1210200016216. Resolución recaída en el Recurso de Revisión RRA 2414/16.

${ }^{21}$ El subrayado es de las autoras.
} 
Mónica Carrasco-Gómez

Hilda E. Argüello-Avendaño
Del dicho al hecho: El seguro popular, su presupuesto y la atención a la salud materna en Chiapas

contar con la información sobre las ministraciones de las transferencias del Anexo IV a las intervenciones de Causes relacionadas con la salud materna y perinatal, porque "los recursos se transfieren con base en las personas afiliadas y no por especialidad, diagnóstico o tratamiento" 22 .

Con la finalidad de conocer en qué metas y actividades se ejerció el dinero, y constatar el desempeño de las mismas para lograr los objetivos en salud, se solicitó información desglosada por meta según las diferentes fuentes de financiamiento - Ramo 12 -AFASPE-, Ramo 33, y Anexo IV - para el año 2015 del estado de Chiapas. ${ }^{23}$

En su respuesta, Isech adjunta dos documentos: uno con información del Programa Anual de Trabajo (PAT) del ejercicio 2015 para Chiapas, que incluye las actividades, presupuesto e indicadores de las estrategias para PAE SMyP. Se mencionan a continuación sólo las que cuentan con presupuesto del Anexo IV: 1.1.1 Brindar consultas prenatales con calidad y seguridad para la usuaria; 1.4.1 Realizar las pruebas de VIH y sífilis a toda mujer embarazada en control, y 5.1.1 Gestionar la adquisición de insumos esenciales para la atención materna y neonatal.

En un segundo documento, Isech proporciona el presupuesto del año 2015 para las intervenciones de Causes que reciben recursos. El documento lleva por nombre "Presupuesto 2015", y tiene los siguientes apartados: entidad federativa, programa, tipo de intervención, clave de intervención, intervención, clave estrategia, estrategia, clave línea de acción, línea de acción, clave actividad, actividad general, clave acción específica, acción específica, clave partida, partida, clave de insumo, insumo, descripción complementaria, fuente de financiamiento, cantidad, precio unitario, total y estatus. Sin embargo, las actividades programadas en PAT no coinciden con los recursos del Anexo IV mencionadas anteriormente. $\mathrm{Al}$ respecto de la intervención de Causes "92. Atención prenatal en el embarazo", se desprende la estrategia "Incrementar el acceso universal en las etapas pre-concepcional, prenatal, parto, puerperio y neonatal a servicios con alta calidad", cuya línea de acción es "Monitorear calidad y seguridad en la atención, con base en evidencias científicas y mejores prácticas, eliminando intervenciones nocivas e innecesarias",

\footnotetext{
${ }^{22}$ Solicitud 1210200016216. Resolución recaída en el Recurso de Revisión RRA 2414/16, pp. 4.

${ }^{23}$ Solicitud con número de folio 15032; respuesta de Isech<: 3 de marzo de 2016.
} 
y la actividad general es "Brindar consultas prenatales con calidad y seguridad para la usuaria”, cuya acción específica corresponde a "Realizar la programación de las necesidades"; esta última se encuentra vinculada con la partida "materiales y útiles de oficina", cuyos insumos fueron la adquisición de dos sellos de goma: \$185.62; 10 paquetes de 100 sobres de papel: $\$ 1,305.50$; cajas de papel para fotocopiadora, todo con un costo total de $\$ 37,260.50$.

En esta misma intervención, estrategia, línea de acción y actividad general, hay otras dos acciones específicas: la primera, "Difusión de mensajes sobre programas y actividades gubernamentales", cuyo insumo tiene la siguiente descripción: "Programar campaña de difusión del programa de salud materna y perinatal", la cual tuvo un costo de $\$ 653,057.44$; y la segunda, "Distribución de los insumos en unidades de salud", cuyo insumo es: "Difusión de mensajes sobre programas y actividades gubernamentales", con la descripción complementaria "Programar campaña de difusión del Programa de Salud Materna y Perinatal”, de costo total $\$ 653,057.44$.

En resumen, la intervención de Causes "92. Atención prenatal en el embarazo" tuvo tres acciones específicas diferentes: 1) realizar programación de necesidades, 2) difusión de mensajes sobre programas y actividades gubernamentales, y 3) distribución de los insumos en unidades de salud, cuyo costo total fue $\$ 1,343,374$, que se gastó finalmente en sellos, papel y campañas de difusión del Programa de Salud Materna y Perinatal.

\section{Discusión}

Entre la diversidad de modelos en la transferencia y gestión de recursos para la salud, de la federación a los estados, algunos poseen características estructurales que favorecen la transparencia y rendición de cuentas, tal es el caso de AFASPE, que cuenta con indicadores y metas estatales, temporalidad explícita, calendario de ministración de recursos, detalle de lo transferido en especie y la obligatoriedad de hacer público el avance de las metas y el ejercicio del gasto. Asimismo, cuenta con una plataforma denominada SIAFFASPE, que es un sistema de administración de información en línea para el registro de datos PAE en materia de 
Mónica Carrasco-Gómez Hilda E. Argüello-Avendaño
Del dicho al hecho: El seguro popular, su presupuesto y la atención a la salud materna en Chiapas

salud pública de los 32 Sesa: "Fue diseñado como una herramienta de planeación y de evaluación del cumplimiento de los objetivos, metas y acciones, así como del ejercicio transparente de los recursos y rendición de cuentas" (Argüello, 2015: 91).

En ese sentido, ACESPSS es un instrumento con características que favorecen la transparencia y la rendición de cuentas, pero su información carece de disponibilidad y accesibilidad para el público en general, limitando la posibilidad de monitorear la programación de necesidades reales de las unidades médicas y el abastecimiento de los insumos para cubrir las necesidades de atención de la población afiliada.

Existen dificultades en Chiapas y en la federación para lograr la transparencia y rendición de cuentas por parte de los responsables de brindar información de SP, esto coincide con la falta de transparencia a nivel municipal que se ha documentado en otras investigaciones (Mendoza, 2015: 112). Al respecto, la resistencia para proporcionar información y hacerla pública tiene que ver con la tradición de opacidad en diversos niveles institucionales (ibídem). Por lo tanto, coincidimos con el hallazgo de Mendoza sobre la "transparencia opaca", —en nuestro caso- en el ejercicio de los recursos de SP en Chiapas; es decir, "existe una brecha entre lo que por disposición legal debería publicarse y la información que está disponible” (Mendoza, 2015: 125).

A pesar de que SP debe brindar protección financiera a las personas que no cuentan con seguridad social, se ha documentado que el gasto de bolsillo de la población no ha disminuido (Molina y Covarrubias, 2015: 148). Esto puede deberse a la falta de calidad de la atención o de recursos e insumos en los servicios de salud (Coneval, 2014: 100), tal como lo han puesto en evidencia los trabajadores de salud en Chiapas que desde 2016 han realizado diversas huelgas, asambleas permanentes y plantones para exigir el abasto de medicamentos e insumos en sus unidades médicas (Martínez, 2016; Gutiérrez, 2016: 7). Incluso han denunciado simulación en el abastecimiento de medicamentos en el estado (Mirada Sur, 2017: 8). Éstos nuevos arreglos para eficientar el llamado ejercicio de los servicios de salud públicos en Chiapas han repercutido negativamente en el ejercicio de los recursos, no sólo por el desabasto mencionado anteriormente sino también por 
falta de pago a los provedores de insumos médicos quienes iniciaron una huelga en enero de 2016 (Estrada, 2016). A partir de estos hechos, coincidimos con los cuestionamientos formulados por Sandoval Ballesteros (2016: 376): ¡estas nuevas formas de organización buscaron promover mayor eficacia en la prestación de servicios de salud o sólo se trata de una nueva cara de la agenda privatizadora de los recursos públicos?

Algunos impulsores de la reforma de salud en México reconocen que pese al aumento de los recursos para la atención en los estados, uno de los desafíos que permanecen es la débil rectoría de SS al producir ineficiencias en el manejo de los recursos (Knaul, 2013: 226). Sin embargo, no se ha analizado en detalle el manejo de los recursos al interior de los estados, es decir, cómo llegan a las unidades médicas o cómo mejorar estas dinámicas opacas e ineficientes. Algunos estudios se limitan únicamente a recomendar directivas sólidas y controles prudentes para evitar la corrupción (ídem: 226).

Aún hace falta información para identificar quiénes se benefician con la separación de funciones, es decir, quién o quiénes reciben y se benefician con la gran cantidad de recursos públicos que se están destinando a la salud vía Anexo IV. En este análisis fue evidente que las empresas privadas, sociedades anónimas y personas físicas, son las que están recibiendo la mayor parte de éstos, lo cual podría favorecer el incremento de la inequidad social en salud fomentada por las reformas neoliberales; este hallazgo coincide con lo documentado en América Latina por Armada y Muntaner (2004: 29).

Esta nueva forma de administrar los recursos, donde un ente articulador público es quien decide a qué empresas otorgar los contratos a nivel local, puede generar conflictos de interés en los servidores públicos, al ser ellos los que deciden a dónde y con quién se destinan los cuantiosos recursos públicos. Las asociaciones público-privadas para la prestación de servicios, compra y distribución de medicamentos e insumos médicos favorece el dispendio y la opacidad, ya que como lo ha documentado Sandoval Ballesteros las políticas de transparencia han fracasado porque en sus "análisis no han tomando en cuenta las complejas estructuras de la autoridad pública”, y propone el enfoque de corrupción estructural cuyo énfasis está en "extender los controles de 
Mónica Carrasco-Gómez

Hilda E. Argüello-Avendaño
Del dicho al hecho: El seguro popular, su presupuesto y la atención a la salud materna en Chiapas

transparencia y combate a la corrupción al ámbito de las corporaciones y el sector privado" (Sandoval Ballesteros, 2016: 367).

Cabe mencionar que hasta el momento lo que produjo el desabasto de los recursos no ha sido identificado y sancionado, lo único que sucede es que a las empresas que no cumplen con lo pactado no se les vuelve a dar un contrato, o en el caso de incumplimiento de pago las empresas dejan de abastecer los insumos, pero ¿qué sucedió con los recursos? No hay información al respecto. Esto muestra que es el erario público el que termina pagando los costos de la ineficiencia en el ejercicio de tales recursos, y las empresas y el Estado quedan libres de asumir la responsabilidad de su inadecuado manejo.

\section{Conclusiones}

Las reformas al sistema de salud mexicano tuvieron como argumento principal eficientar el sistema de salud y disminuir las brechas de acceso para la población más vulnerable mediante la separación de funciones del sistema de salud, creando a nivel estatal organismos descentralizados — REPSS - que controlarían el pago a los prestadores de servicios y a las empresas farmacéuticas y/o distribuidoras. Estas responsabilidades de REPSS para mejorar la transparencia en la ejecución de los recursos no han representado necesariamente una mayor eficiencia del gasto. En el ejercicio del recurso del anexo IV en 2015 fue posible identificar un extravío de lo asignado por más de 60 millones de pesos.

El encargado de realizar la función de articulación es REPSS, responsable de aprobar los proyectos de Isech brindándole suficiencia presupuestal mediante la aprobación de canalizar los recursos desde la federación, lo cual muestra la re-centralización de éstos, ya que el dinero no llega a la Secretaría de finanzas o hacienda estatal, sino que permanece en Tesofe y se transfiere directamente a los proveedores de los insumos y servicios de salud.

El ejercicio del recurso del anexo IV tiene diversas oportunidades de mejora. La información obtenida mostró el detalle de los montos programados, pero no de los ejercidos. $\mathrm{Al}$ respecto, la comprobación de los recursos para las intervenciones de salud materna sigue siendo opaca, debido a que su uso es transversal a otros rubros de gasto, es decir, no se 
fiscalizan los recursos por programas de acción o por intervenciones de Causes. Específicamente, el recurso del Anexo IV se entremezcla con los recursos del Ramo 12 y 33; y los operadores de programa, como en el caso de PAE SMyP, no ven la relevancia de hacer programaciones específicas por fuente de financiamiento.

AFASPE es el único instrumento que muestra los montos asignados por programa y sus diferentes fuentes de financiamiento, incluido el monto proveniente del Anexo IV. Sin embargo, sólo lo hace con fines informativos, pero no es responsable de la aplicación, ejercicio y comprobación de las diferentes fuentes de financiamiento de cada programa.

En algunas páginas institucionales fue posible encontrar el gasto por intervenciones, aunque no se pudo encontrar las relacionadas con la salud materna. Esto pone de manifiesto la falta de homogeneidad en la difusión de la información y la deficiente capacitación de los encargados de responder a las solicitudes de información.

$\mathrm{Al}$ avanzar en las solicitudes de información y recursos de inconformidad encontramos contradicciones en las respuestas, por ejemplo, en una solicitud negaron la información sobre el ejercicio del Anexo IV según intervenciones de salud materna, pero en otra mostraron el ejercicio del recurso de algunas de las intervenciones de Causes en salud materna. Lo ilustrado para Chiapas evidencia que el recurso no se gasta en lo que las unidades médicas necesitan, tanto en respuesta a sus necesidades, como en la distribución de los insumos en las diferentes unidades de salud.

La experiencia de la reforma de salud en Chiapas, con la separación de funciones, la re-centralización del gasto y la función de articulación, no ha logrado eficientar el ejercicio de los recursos. Además la reforma a LGS en materia de Protección Social en Salud de 2014 tampoco logró mejorar la rendición de cuentas ni la distribución de los medicamentos en las unidades médicas chiapanecas, que siguen manifestando ineficiencias en su funcionamiento, malestar en los prestadores de servicios y falta de provisión de servicios a la población. 
Mónica Carrasco-Gómez

Hilda E. Argüello-Avendaño
Del dicho al hecho: El seguro popular, su presupuesto y la atención a la salud materna en Chiapas

\section{Bibliografía citada}

Argüello-Avendaño, Hilda Eugenia, 2017, "Breve historia sobre política pública y sus estrategias para la reducción de la muerte Materna”, en Graciela Freyermuth Enciso (coordinadora), Salud y mortalidad materna en México. Balances y perspectivas desde la antropología y la interdisciplinariedad, Centro de Investigaciones y Estudios Superiores en Antropología Social, México, pp. 17-61. Argüello-Avendaño, Hilda Eugenia, s/f, Mortalidad materna a principios del siglo XXI en los altos de Chiapas, México: violencia estructural y buisqueda de atención, Tesis de doctorado [en proceso de revisión final], Departament d'Antropologia, Filosofia i Treball Social, Universitat Rovira i Virgili, Tarragona, Catalunya, España.

Armada, Francisco y Carles Muntaner, 2004, "The Visible Fist of the Market: Health Reforms in Latin America”, en Arachu Castro y Merrill Singer (editores), Unhealthy health policy. A critical Anthropological Examination, AltaMira Press, U.S., United Kingdom, pp. 29-41.

Arredondo, Armando y Ana Lucía Recaman Mejía, 2003, "El financiamiento de la salud en México: Algunas evidencias para las políticas del sector", Hitos de Ciencias Económico Administrativas, año 9, núm. 23, pp. 9-16, enero-abril.

Auditoria Superior de la Federación, 2013, "Diagnóstico sobre la opacidad en el gasto federalizado", Cámara de diputados, Gobierno de México, [en línea] disponible en http://www.asf.gob.mx/ uploads/56_Informes_especiales_de_auditoria/Diagnostico_sobre_la_Opacidad_en_el_Gasto_Federalizado_version_final. pdf\%0D [fecha de consulta: 17 de marzo de 2016].

Banco Internacional de Reconstrucción y Fomento y Banco Mundial, 1993, Informe sobre el desarrollo mundial 1993. Invertir en salud, Banco Mundial, Washington D.C.

Bobadilla, J.L., P. Cowley, P. Musgrove \& H. Saxenian, 1995, “Diseño, contenido y financiamiento de un paquete nacional de servicios de salud esenciales", Bol. Oficina Sanit Panam, vol. 118, núm. 2, pp. 127-140. 
CNPSS, 2014, “Compra de servicios. Tercer trimestre de 2014”, [en línea] disponible en http://sistemas.cnpss.gob.mx:7000/data mart/index.php/dm_servicios/index/201403 [fecha de consulta: 20 de diciembre de 2016].

CNPSS, 2016, Comité de transparencia. Vigésima cuarta sesión extraordinaria celebrada el día 13 de diciembre de 2016, expediente RRA 3558/16, Solicitud de información: 1210200018016 , Ciudad de México, 14 de diciembre.

Coneval, 2014, "Informe de evaluación de la política de desarrollo social en México 2014", México, [en línea] disponible en http:// www.coneval.gob.mx/Informes/Evaluación/IEPDS_2014/ IEPDS_2014.pdf [fecha de consulta: 11 de mayo de 2017].

Díaz Echeverría, Daniela, 2012, "El presupuesto para salud y mortalidad materna: una cuestión de derechos", [en línea] disponible en http://cdhdfbeta.cdhdf.org.mx/wp-content/uploads/2014/05/ dfensor_03_2012.pdf [fecha de consulta: 26 de noviembre de 2017].

Estrada, H., 2016, “Gobierno de Chiapas ¿en guerra con acreedores?”, El Estado, [en línea] http://www.agenciaelestado.com.mx/gobierno-de-chiapas-en-guerra-con-acreedoresen-la-mira/\#

Fernández, Mariana, 1993, "Políticas del Estado Mexicano en Salud Reproductiva durante el periodo de 1970 a 1990, Chiapas", documento interno, Grupo de Mujeres de San Cristóbal de Las Casas, A.C., San Cristóbal de Las Casas, Chiapas.

Freedman, Lynn P., 2003, "Human rights, constructive accountability and maternal mortality in the Dominican Republic", International Journal of Gynecology \& Obstetrics, vol. 82, núm. 1, pp. 111-114.

Freyermuth Enciso, María Graciela, Héctor Javier Pérez Sánchez y Hilda Eugenia Argüello Avendaño, 2014,“Transparencia y rendición de cuentas en salud materna: el caso del AFASPE en Chiapas", Revista Pueblos y fronteras digital, vol. 9, núm. 17, pp. 79-93, [en línea] disponible en http://www.redalyc.org/articulo.oa?id=90630737006 [fecha de consulta: 27 de noviembre de 2016]. 
Mónica Carrasco-Gómez

Hilda E. Argüello-Avendaño
Del dicho al hecho: El seguro popular, su presupuesto y la atención a la salud materna en Chiapas

Gutiérrez, Óscar, 2016, "Finalizan trabajadores de la salud paro de labores en Chiapas", disponible en htpp://www.eluniversal.com. $\mathrm{mx} /$ articulo/estados/2016/07/7/ [fecha de consulta: 8 de julio de 2016].

Human Rights Watch, 2009, "No Tally of the Anguish Accountability in Maternal Health Care in India”, [en línea] disponible en https:// www.hrw.org/sites/default/files/reports/india1009web_0.pdf [fecha de consulta: 26 de noviembre de 2017].

Ibarra, Ignacio, Gabriel Martínez, Nelly Aguilera, Emanuel Orozco, Germán Fajardo-Dolci, Miguel Ángel González-Block, 2013, "Capacidad del marco jurídico de las instituciones públicas de salud de México para apoyar la integración funcional”, Salud Pública de México, vol. 55, núm. 3, pp. 310-317, mayo-junio.

Instituto Nacional de Salud Pública, 2008, Evaluación del Sistema de Protección Social en Salud, 2007, Secretaría de Salud. México, 2008, pp. 23-24.

Knaul, Felicia Marie et al., 2013, "Hacia la cobertura universal en salud: protección social para todos en México", Salud pública de México, vol. 55, núm. 2, pp. 207-235.

Langford, Malcom, 2008, "Reivindicar los objetivos de desarrollo del milenio: un enfoque de derechos humanos", Naciones Unidas, Nueva York, [en línea] disponible en http://www.ohchr. org/Documents/Publications/MDGs_part_1_sp.pdf [fecha de consulta: 29 de noviembre de 2017].

Laurell Asa, Cristina, 2001, Mexicanos en defensa de la salud y la seguridad social. Cómo garantizar y ampliar tus conquistas históricas, Editorial Planeta Mexicana, México, pp. 15-35.

Laurell Asa, Cristina y Joel Herrera Ronquillo, 2010, "La Segunda Reforma de Salud. Aseguramiento y compra-venta de servicios", Salud Colectiva, año 6, núm 2, pp.137-148.

Londoño, Juan Luis y Julio Frenk, 1997, "Pluralismo estructurado: hacia un modelo innovador para la reforma de los sistemas de salud en América Latina”, Working Paper, Inter-American Development Bank, Office of the Chief Economist. 
López, D., 1981, La salud desigual en México, 2a edición, Siglo veintiuno editores, México.

Malajovich, Laura, María Antonieta Alcalde, Kelly Castagnaro y Carmen Barroso, 2012, "Presupuestos transparentes para el gasto en atención de salud materna: Estudio de caso en cinco países latinoamericanos", Repolitizar la salud y los derechos sexuales y reproductivos, vol. 20, núm. 39, p. 185 [en línea] disponible en http://www.diassere.org.pe/wp-content/static/pdf/rhm7_6.pdf [fecha de consulta: 27 de noviembre de 2017].

Martínez, Manuel, 2016, "Por falta de medicinas y equipo médico, realizan plantón en hospitales", Mirada Sur, 10 de junio.

Mendoza Pérez, Juan, 2015, "Transparencia opaca en los gobiernos municipales: una difícil transición hacia una política pública”, en Juan Mendoza Pérez y José María Martinelli (coordinadores), Reformas Estructurales: Privatización y Despojo Social, México, D.F., pp. 99-128.

Molina Salazar, Raúl y Jaqueline Covarrubias Zenil, 2015, “El desafío de la universalización de servicios de salud en México", en Juan Mendoza Pérez y José María Martinelli (coordinadores), Reformas Estructurales: Privatización y Despojo Social, México, D.F., pp. 129-151.

Morales Domínguez, Magdalena del Carmen, Guadalupe Sánchez Ramírez \& Edith Francoise Kauffer Michel, 2011, "Elementos del presupuesto del Seguro Popular en Chiapas desde el enfoque de género", Politica y cultura, núm. 35, pp. 161-182.

Mural Chiapas, 2017, "Simulación en abastecimiento de medicamentos en Chiapas", Mirada Sur, 4 de febrero, p. 8.

Musgrove, P. y Miguel Ángel González Block, 2007, "La integración funcional del Sistema de Salud de México: algunas consideraciones preliminares", Foro de Liderazgo en Salud. Hacia la Integración Sectorial, Ciudad de México, en Ignacio Ibarra, Gabriel Martínez, Nelly Aguilera, Emanuel Orozco, Germán FajardoDolci, Miguel Ángel González-Block, 2013, “Capacidad del marco jurídico de las instituciones públicas de salud de México 
Mónica Carrasco-Gómez

Hilda E. Argüello-Avendaño
Del dicho al hecho: El seguro popular, su presupuesto y la atención a la salud materna en Chiapas

para apoyar la integración funcional”, Salud Pública de México, vol. 55, núm. 3, pp. 310-317, mayo-junio.

Observatorio de Mortalidad Materna en México, Tercer monitoreo 2015, Convenio General de Colaboración interinstitucional para la atención de la emergencia obstétrica, OMM, CIESASSureste, San Cristóbal de Las Casas, Chiapas, México, [en línea] disponible en http://www.omm.org.mx/images/stories/ Documentos\%20grandes/Sintesis_general_25abr.pdf [fecha de consulta: 10 de enero de 2017].

Organización de las Naciones Unidas, 2006, Relator Especial sobre el Derecho a la Salud, Informe del Relator Especial sobre el derecho de toda persona al disfrute del más alto nivel posible de salud física y mental ante la Asamblea General de las Naciones Unidas, UN Doc. A/61/338, 61 Periodo de Sesiones, [en línea] disponible en http://observatoriopoliticasocial.org/ sitioAnterior/images/PDF/Biblioteca/biblioteca_2010/ONU_ docs/Informes_relatores/Salud/2006_informe_del_relator_especial_sobre_el_derecho_a_la_salud_fsica_y_mental.pdf [fecha de consulta: 26 de noviembre de 2017].

Organización Mundial de la Salud, 2000, "Mejorar el desempeño de los sistemas de salud. Informe sobre la salud en el mundo", 53a Asamblea Mundial de la Salud, A53/4, 230 pp.

Organización para la Cooperación y el Desarrollo Económicos, 2015, Panorama de la Salud 2015. Indicadores de la OCDE, Organización para la Cooperación y el Desarrollo Económicos, París. Sandoval Ballesteros, Irma Eréndira, 2016 "Corruption and Organizational Challenges in a World of Public-Private Partnerships", Gestión y política pública, vol. 25, núm. 2, pp. 365-413.

Secretaría de Salud, 2002, "Programa de Acción Arranque Parejo en la Vida”, México.

Secretaría de Salud, 2011, Acuerdo general de colaboración para el intercambio de servicios, México.

Secretaría de Salud, 2015, Acuerdo de coordinación para la ejecución del Seguro Popular en Chiapas, México.

Secretaría de Salud del Estado de Chiapas, 2015, Resolución 13565. 
Del dicho al hecho: El seguro popular, su presupuesto y la atención

a la salud materna en Chiapas

Sotelo Velázquez, Andrés Jesús, 2016a, Titular de la unidad de Transparencia CNPSS, Solicitud de información 1210200016216.

Sotelo Velázquez, Andrés Jesús, 2016b, Titular de la unidad de Transparencia, Solicitud de información: 1210200018016.

Yamin, Alicia, 2010, "Hacia una rendición de cuentas transformadora: aplicando un enfoque de derechos humanos para satisfacer las obligaciones en relación a la salud materna”, Revista Sur, núm. 7, pp. 99-127.

Watzkin Howard, 2013, Medicina y salud pública al final del imperio, Universidad Nacional de Colombia, Bogotá.

SigLAS Y ACRÓNIMOS

\begin{tabular}{|l|l|}
\hline ACEPSS & $\begin{array}{l}\text { Acuerdo de Coordinación para la Ejecución de } \\
\text { Sistema de Protección Social en Salud }\end{array}$ \\
\hline AFASPE & $\begin{array}{l}\text { Acuerdo para el Fortalecimiento de las Acciones de } \\
\text { Salud Pública en los Estados }\end{array}$ \\
\hline ASF & Auditoria Superior de la Federación \\
\hline Causes & Catálogo Universal de Servicios de Salud \\
\hline CGCIAEO & $\begin{array}{l}\text { Convenio General de Colaboración } \\
\text { Interinstitucional para la Atención de la } \\
\text { Emergencia Obstétrica }\end{array}$ \\
\hline CNEGSR & $\begin{array}{l}\text { Centro Nacional de Equidad de Género y Salud } \\
\text { Reproductiva }\end{array}$ \\
\hline CNPSS & Comisión Nacional de Protección Social en Salud \\
\hline DGSS & $\begin{array}{l}\text { Dirección General de Gestión de Servicios de } \\
\text { Salud }\end{array}$ \\
\hline DIF & $\begin{array}{l}\text { Sistema Nacional para el Desarrollo Integral de la } \\
\text { Familia }\end{array}$ \\
\hline FIUM & $\begin{array}{l}\text { Fortalecimiento de Infraestructura de Unidades } \\
\text { Médicas }\end{array}$ \\
\hline FPGC & Fondo de Protección contra Gastos Catastróficos \\
\hline IF & Integración Funcional \\
\hline IMSS & Instituto Mexicano del Seguro Social \\
\hline
\end{tabular}




\begin{tabular}{|l|l|}
\hline Inai & $\begin{array}{l}\text { Instituto Nacional de Transparencia, Acceso a la } \\
\text { Información y Protección de Datos Personales }\end{array}$ \\
\hline Isech & Instituto de Salud del Estado de Chiapas \\
\hline ISSSTE & $\begin{array}{l}\text { Instituto de Seguridad y Servicios Sociales de los } \\
\text { Trabajadores del Estado }\end{array}$ \\
\hline LGS & Ley General de Salud \\
\hline OCDE & $\begin{array}{l}\text { Organización para la Cooperación y el Desarrollo } \\
\text { Económicos }\end{array}$ \\
\hline OMM & Observatorio de Mortalidad Materna en México \\
\hline ONU & Organización de las Naciones Unidas \\
\hline PAE APV & $\begin{array}{l}\text { Programa de Acción Específico Arranque Parejo en } \\
\text { la Vida }\end{array}$ \\
\hline PAE SMyP & $\begin{array}{l}\text { Programa de Acción Específico Salud Materna y } \\
\text { Perinatal }\end{array}$ \\
\hline PAT & Programa Anual de Trabajo \\
\hline PEF & Presupuesto de Egresos de la Federación \\
\hline Pemex & Petróleos Mexicanos \\
\hline REPSS & Régimen Estatal de Protección Social en Salud \\
\hline Semar & Secretaría de Marina \\
\hline Sesa & Servicios Estatales de Salud \\
\hline SIAFFASPE & $\begin{array}{l}\text { Sistema de Información para la Administración } \\
\text { del Fondo para el Fortalecimiento de Acciones de } \\
\text { Salud Pública en las Entidades Federativas }\end{array}$ \\
\hline SNS & Sistema Nacional de Salud \\
\hline SP & $\begin{array}{l}\text { Subsecretaría de Prevención y Promoción de la } \\
\text { Salud }\end{array}$ \\
\hline SPPS & Sistema de Protección Social en Salud \\
\hline SPSS & Secretaría de Salud \\
\hline SS & Secretaría de Salubridad y Asistencia \\
\hline SSA & Tesorería de la Federación \\
\hline Tesofe & Virus de Inmunodeficiencia Humana \\
\hline VIH & \\
\hline
\end{tabular}

